\title{
Genome-wide screening in human growth plates during puberty in one patient suggests a role for RUNX2 in epiphyseal maturation
}

\author{
Joyce Emons, Bas E Dutilh ${ }^{1}$, Eva Decker ${ }^{2}$, Heide Pirzer ${ }^{2}$, Carsten Sticht ${ }^{3}$, Norbert Gretz ${ }^{3}$, \\ Gudrun Rappold ${ }^{2}$, Ewan R Cameron ${ }^{4}$, James C Neil ${ }^{4}$, Gary S Stein ${ }^{5}$, Andre J van Wijnen ${ }^{5}$, \\ Jan Maarten Wit, Janine $\mathbf{N}$ Post $^{6}$ and Marcel Karperien ${ }^{6}$
}

\author{
Department of Paediatrics, Leiden University Medical Center, 2300 ZA Leiden, The Netherlands \\ ${ }^{1}$ Centre for Molecular and Biomolecular Informatics, Radboud University Nijmegen Medical Center, 6525 GA Nijmegen, The Netherlands \\ ${ }^{2}$ Department of Human Molecular Genetics, University of Heidelberg, Heidelberg 69120, Germany \\ ${ }^{3}$ Medical Research Center, Medical Faculty Mannheim, Mannheim D-68167, Germany \\ ${ }^{4}$ Molecular Oncology Laboratory, Faculty of Veterinary Medicine, Institute of Comparative Medicine, University of Glasgow, Glasgow G12 8QQ, UK \\ ${ }^{5}$ Department of Cell Biology, University of Massachusetts Medical School, Worcester, Massachusetts 01655, USA \\ ${ }^{6}$ Department of Tissue Regeneration, University of Twente, 7522 NB Enschede, The Netherlands \\ (Correspondence should be addressed to J Emons; Email: j.emons@lumc.nl)
}

\begin{abstract}
In late puberty, estrogen decelerates bone growth by stimulating growth plate maturation. In this study, we analyzed the mechanism of estrogen action using two pubertal growth plate specimens of one girl at Tanner stage B2 and Tanner stage B3. Histological analysis showed that progression of puberty coincided with characteristic morphological changes: a decrease in total growth plate height $(P=0 \cdot 002)$, height of the individual zones $(P<0 \cdot 001)$, and an increase in intercolumnar space $(P<0 \cdot 001)$. Microarray analysis of the specimens identified 394 genes (72\% upregulated and $28 \%$ downregulated) that changed with the progression of puberty. Overall changes in gene expression were small (average 1.38-fold upregulated and 1.36-fold downregulated genes). The 394 genes mapped to 13
\end{abstract}

significantly changing pathways $(P<0 \cdot 05)$ associated with growth plate maturation (e.g. extracellular matrix, cell cycle, and cell death). We next scanned the upstream promoter regions of the 394 genes for the presence of evolutionarily conserved binding sites for transcription factors implicated in growth plate maturation such as estrogen receptor (ER), androgen receptor, ELK1, STAT5B, cyclic AMP response element (CREB), and RUNX2. High-quality motif sites for RUNX2 (87 genes), ELK1 (43 genes), and STAT5B (31 genes), but not ER, were evolutionarily conserved, indicating their functional relevance across primates. Moreover, we show that some of these sites are direct target genes of these transcription factors as shown by ChIP assays.

Journal of Endocrinology (2011) 209, 245-254

\section{Introduction}

Longitudinal growth occurs at the epiphyseal growth plate, a thin layer of cartilage between epiphyseal and metaphyseal bone at the distal ends of the long bones. In the normal growth plate, immature cells are located toward the epiphysis, called the resting zone, with mature chondrocytes in the proliferating zone, which dramatically increase in size in the hypertrophic zone adjacent to this (Kronenberg 2003). At the beginning of puberty, the longitudinal growth rate first increases, but with progression of puberty, the growth rate decelerates due to growth plate maturation, and eventually, at the end of puberty, the growth plate disappears due to epiphyseal fusion. The molecular mechanisms underlying these distinct phases are largely unknown, but a role for estrogen has been suggested (MacGillivray et al. 1998, Chagin \& Savendahl 2007a).
Endocrinological observations suggest that the growth spurt is initiated at the beginning of puberty by relatively low levels of estrogen. The increase in estrogen levels that occur with the progression of puberty drives growth plate maturation and finally growth plate fusion. The most compelling evidence for the role of estrogen is provided by clinical observations in a patient with an inactivating mutation in the estrogen receptor $\alpha(\mathrm{ER} \alpha)$ and in patients with a mutation in the aromatase gene resulting in lack of estrogen. These patients did not experience a growth spurt and lacked growth plate maturation and fusion (Smith et al. 1994, Morishima et al. 1995). Furthermore, clinical observations have shown that high levels of estrogen inhibit longitudinal bone growth (Turner et al. 1994).

The mechanism by which estrogens exert these effects on growth plate activity is not fully understood. It has been postulated that estrogen accelerates the senescent decline of the 
growth plate (Weise et al. 2001). Senescence is a term for the structural and functional changes over time in the growth plate, such as a gradual decline in the overall growth plate height, proliferative zone height, hypertrophic zone height, size of hypertrophic chondrocytes, proliferation rate, and column density (Weise et al. 2001). It is believed that the growth plate fuses when senescence reaches a critical point. Recent evidence indicates that senescence might occur because stem-like cells in the resting zone have a finite proliferative capacity, which is gradually exhausted. This process is accelerated by estrogen (Gafni et al. 2001, Schrier et al. 2006).

Estrogen induces cell responses by activating the so-called genomic signaling pathway involving the nuclear $\operatorname{ER} \alpha$ and ER $\beta$ (Greene et al. 1986). Moreover, estrogen also works through a non-genomic signaling pathway involving membrane-bound receptors like GPR30, resulting in the activation of adenylyl cyclases and MAPKs (Filardo et al. 2002). In addition, Teplyuk et al. (2008) describe a direct role for Runx2 in G-protein-coupled signaling for controlling growth of osteoblast progenitor cells. ER $\alpha, \operatorname{ER} \beta$, and GPR 30 are all expressed in human growth plate chondrocytes (Nilsson et al. 2003, Chagin \& Savendahl 2007b). Their expression is not limited to the stem-like cells of the resting zone, which are the main target cells of estrogen action based on the senescence hypothesis, but is more broadly distributed in the growth plate. It is still largely unknown whether the pubertal phenomena in relation to growth rate are caused by direct effects of estrogen on chondrocytes or by indirect effects via, for example, activation of the $\mathrm{GH} /$ insulin-like growth factor 1 (IGF1) axis.

During puberty, the levels of both sex steroids, GH and IGF1, increase (Perry et al. 2008). It is well known that GH and IGF1 can increase growth velocity and accelerate bone maturation measured by a decrease in growth plate height in children (de Zegher et al. 1997, Kamp et al. 2002). Moreover, human chondrocytes contain receptors for GH and IGF1 (Werther et al. 1993), indicating that both hormones can have direct effects on the growth plate. Stimulation of the GH receptor activates an intracellular signal transduction cascade eventually converging to the transcription factor STAT5B (Rosenfeld \& Hwa 2009). Likewise, IGF1 signaling results in the activation of signaling routes involving, for example, the transcription factor ELK1 (Bruning et al. 2000). The exact contributions of these hormones in growth plate maturation and epiphyseal fusion remain to be elucidated.

Alternatively, estrogen may directly or indirectly regulate the expression of paracrine regulators of growth plate activity such as parathyroid hormone-related peptide (PTHrP) and Indian hedgehog (Ihh). These secreted growth factors coordinate endochondral ossification by regulating chondrocyte proliferation and differentiation as well as osteoblast differentiation (van der Eerden et al. 2000, Karp et al. 2000). PTHrP signals exert their influence by activating the cyclic AMP response element (CREB) binding protein (Mak et al. 2008). Both factors have been identified in the postnatal growth plate and have been postulated to play a role in growth plate fusion (Kindblom et al. 2002).
The transcription factor Runx 2 plays an important role in the growth plate by regulating chondrocyte hypertrophy and the associated changes in the extracellular matrix (ECM; Yoshida \& Komori 2005). The expression and activation of this transcription factor is in part regulated by PTHrP and Ihh (Yoshida et al. 2004).

Studies on the regulation of growth plate activity during puberty are hampered by the lack of easily accessible and representative animal models. For example, in rodents, growth plates are not fused at the end of sexual maturation and discrepancies exist between human and mouse models with respect to the role of $E R \alpha$ in growth plate regulation (Smith et al. 1994, Vidal et al. 1999, Nilsson et al. 2003). In addition, human growth plate specimens are very difficult to obtain.

We were fortunate to obtain growth plate samples of a single patient at two different stages of puberty. The growth plate tissues are genetically identical and from the same anatomical location. In this study, we have performed a morphological analysis of these growth plate specimens complemented with a detailed microarray and bioinformatic analysis and identified 394 differentially expressed genes, some of which are representative for processes that occur during growth plate maturation. We subsequently searched the promoter regions of these genes for evidence of involvement of hormones and paracrine factors in their expression regulation during growth plate maturation. Assuming that the regulation of processes such as growth plate maturation is conserved across primates, we identified functional transcription factor binding sites as those motif sites with a better evolutionary conservation than sites occurring by chance, related to phylogenetic footprinting (Tagle et al. 1988, Kouwenhoven et al. 2010). In this study, we searched the promoter regions of genes that were differentially expressed in the two growth plate specimens for evidence of direct effects of estrogen, androgen, GH, IGF1, PTHrP, and RUNX2 on their expression. Next, we compared the predicted transcription factor binding with transcription factor binding data from ChIP assays and RNA interference experiments to verify the interaction of transcription factors with the regulatory region of these target genes.

\section{Materials and Methods}

This study was approved by the local medical ethical committee and informed consent was obtained. Two epiphyseal growth plate samples, from the left and the right proximal femur, were obtained from the same girl with a 1-year interval. In this period, the girl progressed from early (Tanner stage B2) at age 12.5 years to a progressed stage of puberty (Tanner stage B3) at age 13.5 years. The patient suffered from cerebral palsy and underwent resection of her femur head twice because of painful luxations. She did not use any long-term medication. Both the epiphyseal samples were longitudinally cut with a bone saw and the pieces were 
covered by Tissue-Tek (Sakura Finetek Europe B.V., Zoeterwoude, The Netherlands), directly frozen in liquid isopentane, and stored at $-80{ }^{\circ} \mathrm{C}$ or fixed in $10 \%$ formalin, decalcified with EDTA and embedded in paraffin.

\section{Histological analysis}

Paraffin-embedded samples were cut into longitudinal $5 \mu \mathrm{m}$ thick sections using a Reichert Jung 2055 microtome (Leica, Rijswijk, The Netherlands). The sections were mounted on glass slides and stained with hematoxylin. Total height was measured at three points parallel to the chondrocyte columns, height of each zone was measured at ten different places for each zone, and results were averaged. The space between columns in the proliferative and hypertrophic zone was measured at 20 different places.

\section{RNA isolation}

Bone was removed from both epiphyseal growth plate samples and $40 \mu \mathrm{m}$ thick sections were cut with a cryostat. Every fifth section was followed by a $5 \mu \mathrm{m}$ thick section, which was studied with hematoxylin staining to ensure lack of bone contamination. Total RNA isolation was performed with an optimized method for RNA extraction from cartilage as described by Heinrichs et al. (1994), except that the protocol was started by homogenizing the sections in $1 \mathrm{ml}$ guanidine thiocyanate solution. RNA extraction was followed by purification with a RNeasy kit according to the manufacturer's protocol (Qiagen) and quality and integrity of each sample were checked with the Agilent 2100 Bioanalyzer.

\section{Microarray}

RNA was tested by capillary electrophoresis on an Agilent 2100 bioanalyzer (Agilent Technologies, Santa Clara, CA, USA) and high quality was confirmed. Total RNA (100 ng) was then amplified and labeled using the GeneChip TwoCycle cDNA Synthesis Kit (Affimetrix, High Wycombe, UK) and the MEGAscript T7 Kit (Ambion/Applied Biosystem, Carlsbad, CA, USA). The labeled cRNA was further used for the hybridization to Affymetrix Human Genome U133 PLUS 2.0 Array Genechips and hybridized according to Affymetrix manufacturer's protocol. RNA was extracted from two different sections of each growth plate. A Custom CDF version 11 with Entrez-based gene definitions was used to annotate the arrays (Sandberg \& Larsson 2007). The raw fluorescence intensity values were normalized applying quantile normalization using a commercial software package SAS JMP7 Genomics, version 3.1, from SAS (SAS Institute, Cary, NC, USA). Gene annotation was obtained through the Affymetrix NetAffx web site (http://www.affymetrix.com/ analysis/index.affx). The quality control, normalizations, and statistical modeling were performed by array group correlation, mixed model normalization, and mixed model analysis respectively. For the presence/absence analysis for a single array, GeneChip Operating Software version 1.4 (GCOS; Affymetrix) was used. Analysis of differential gene expression was based on loglinear mixed model of perfect matches (Chu et al. 2002). A false discovery rate of $a=0 \cdot 05$ with FDR correction for multiple testing was used to make a selection of most differentially expressed genes. These affected genes were further investigated to identify pathways that are likely to be affected by differential expression. Pathways were generated either from the Kyoto Encyclopedia of Genes and Genomes (KEGG) database (http://www.genome.ad.jp/kegg/pathway. html) or from the manual annotation. The selection of affected genes were also analyzed with a genome-wide analysis of gene sets defined by the Gene Ontology (GO) Consortium and classified as GO terms (Beissbarth 2006). In this analysis, an enrichment of affected genes within a GO term suggests that this GO term is affected by maturation of the growth plates. Analyses were done with the Gene Ontology Tree Machine program (http://bioinfo.vanderbilt. edu/gotm). The raw and normalized data are deposited in the Gene Expression Omnibus database (http://www.ncbi.nlm. nih.gov/geo/; accession No. GSE-18338).

\section{Reverse transcription-PCR}

RNA was reverse transcribed into cDNA using First Strand cDNA Synthesis kit for qPCR (Roche Diagnostics Gmbh) according to the manufacturer's instructions. Expression of collagen 3A1 (COL3A), CDKN1B (p27Kip1), dolichylphosphate mannosyltransferase polypeptide 1 (DPM1), thrombospondin 4 (THBS4), and ribosomal protein L15 (RPL15) mRNA was quantified by real-time PCR using the Bio-Rad iCycler with SYBR Green. QuantiTect Primer Assays for each of these genes were purchased from Qiagen (Qiagen Benelux B.V.) and used according to the manufacturer's protocol. Threshold cycles were estimated and averaged for the triplicates. Relative amounts of mRNA were normalized to $\beta_{2}$-microglobulin expression in the same sample to account for variability in the initial concentration, quality of total RNA, and in the efficiency of the reverse transcription reaction. $\Delta C_{t}$ was calculated by extracting the threshold cycle for $\beta_{2}$-microglobulin from the threshold cycle for the gene of interest followed by calculation of the change in $\Delta C_{\mathrm{t}}$ with progression of puberty.

\section{Transcription factor binding sites}

Upstream regions of 5000nt were downloaded from the 394 genes that changed with progression of puberty. The promoter regions were scanned for six well-described transcription factor binding motifs selected from Jaspar 3.0 (Sandelin et al. 2004) and Transfac 7.0 (http://www.generegulation.com). The motifs were (Supplementary Table 1, see section on supplementary data given at the end of this article) ER (Jaspar MA0112; Welboren et al. 2009), androgen receptor (Jaspar MA0007; Roche et al. 1992), ELK1 (Transfac M00025; Treisman et al. 1992), CREB (Jaspar MA0018; 


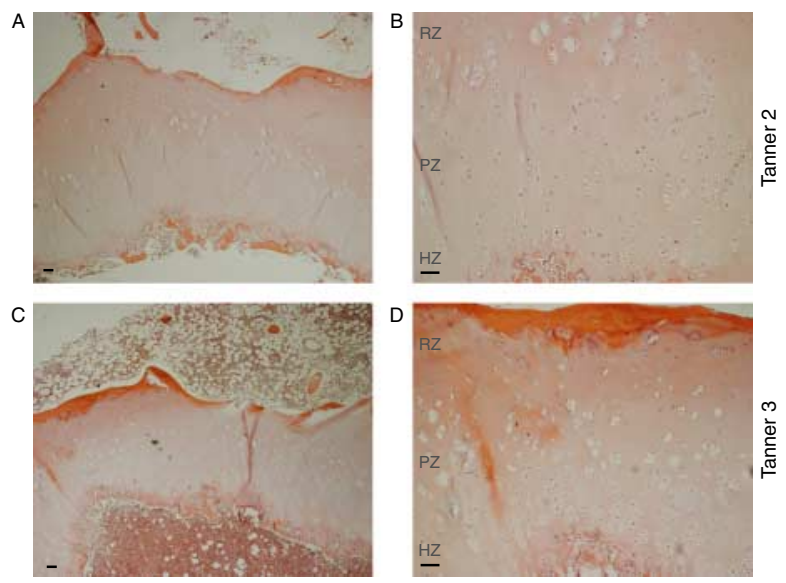

Figure 1 Histology of growth plate Tanner stage B2 and Tanner stage B3. Panels A and B: pictures of growth plate of patient in Tanner stage B2 in $40 \times$ and $100 \times$ magnification respectively. Panels C and D: pictures of growth plate of patient in Tanner stage B3 in $40 \times$ and $100 \times$ respectively magnification. The more mature growth plate (Tanner stage B3) shows a decrease in total growth plate height, a decrease in height of each separate zone, and an increase in the mean space between columns. RZ, resting zone; $\mathrm{PZ}$, proliferative zone; $\mathrm{HZ}$, hypertrophic zone. Bars indicate $200 \mu \mathrm{m}$. Full colour version of this figure available via http://dx.doi. org/10.1530/JOE-10-0219

Portales-Casamar et al. 2007), Runx2 (Jaspar MA0002), and STAT5B (Transfac M00459; Soldaini et al. 2000). The highest scoring positions were selected as potential regulatory sites. Two types of randomization controls were included. First, we scanned the $5000 \mathrm{nt}$ upstream regions of 100 sets of 394 randomly chosen genes for the six motifs mentioned above (random genes). Secondly, we scanned the 5000nt upstream regions of the 394 differentially expressed genes for 100 versions of the six motifs with randomized columns (random motifs).

Because we expected that meaningful binding sites may be distinguished from spurious high-scoring hits by their evolutionary conservation (Kouwenhoven et al. 2010), we assessed the conservation of each of the binding sites across nine primate genomes. For this purpose, the PhastCons (Siepel et al. 2005) primates conservation track was downloaded from the UCSC Genome Browser download page (Kuhn et al. 2009) and the average conservation score for all positions aligned with the motif were calculated.

\section{Results}

\section{Quantitative histology}

Histology of the samples showed a clear decrease in overall height of the growth plate at the more progressed stage of puberty (Fig. 1). This was confirmed by quantitative measurements showing a significant decrease in the average height of the growth plate and a significant decrease in the height of the resting, proliferative, and hypertrophic zone at Tanner stage 3 . The mean space between columns was increased in the more mature growth plate. These data are summarized in Table 1.

\section{Gene expression microarray analysis}

RNA of both growth plate samples was amplified, labeled, and subjected to Affymetrix microarray analysis (HG-U133 Plus 2) in duplicate. The technical and biological reproducibility was good, with correlations above 0.97. The raw and normalized data are deposited in the Gene Expression Omnibus database (http://www.ncbi.nlm.nih.gov/geo/; accession no. GSE-18338). The presence and absence analysis for each probe set was employed by using the GeneChip Operating Software version 1.4 (GCOS) from Affymetrix. On average, 5043 genes were present; with the progression of puberty, the number of genes present in the growth plate slightly increased (5069 vs 5016) (Table 2).

The microarray data was validated by quantitative PCR (qPCR) for five randomly chosen genes. Similar trends in gene expression (up- or downregulation) were found in qPCR and microarray analysis for all genes (Fig. 2). THSB4 showed a more pronounced increase in expression in the microarray results compared with the qPCR results.

Analysis with a loglinear mixed model of perfect matches and a false discovery rate of $a=0 \cdot 05$ and a Bonferroni correction for multiple testing revealed 460 affymetrix probe IDs changing in expression, of which 330 were upregulated and 130 were downregulated. Using BioMart 0.7 (Haider et al. 2009), these probes were mapped to 394 genes changing with maturation of the growth plate (Supplementary Table 2, see section on supplementary data given at the end of this article). The overall changes in gene expression were small: on average, $1 \cdot 38$-fold increase for upregulated and 1.36-fold decrease for downregulated genes. Cytokine-like 1 was the

Table 1 Quantitative histology growth plate Tanner stage B2 and B3. Table showing measurements of total height, height of each individual zone, and intercolumn space of the growth plate in Tanner stage B2 and the more progressed growth plate in Tanner stage B3. The relative distribution of the different zones is given in percentage of the total height of the growth plate

Total height $(\mathrm{mm})$

Height resting zone $(\mathrm{mm})$ Height proliferative zone $(\mathrm{mm})$ Height hypertrophic zone $(\mathrm{mm})$ Intercolumn space $(\mathrm{mm})$

$\begin{array}{ccc}\text { Tanner stage B2 } & & \% \\ 0 \cdot 16 \pm 0 \cdot 01 & \\ 0 \cdot 073 \pm 0 \cdot 003 & & 46 \\ 0 \cdot 047 \pm 0 \cdot 003 & & 29 \\ 0 \cdot 024 \pm 0 \cdot 003 & & 15 \\ 4 \cdot 87 \times 10^{-4} \pm 0 \cdot 34 \times 10^{-4} & \end{array}$

\begin{tabular}{|c|c|c|}
\hline Tanner stage B3 & $\%$ & $P$ value \\
\hline $0 \cdot 097 \pm 0 \cdot 012$ & & $0 \cdot 002$ \\
\hline $0.037 \pm 0.009$ & 38 & $<0.001$ \\
\hline $0.033 \pm 0.004$ & 34 & $<0.001$ \\
\hline $0.016 \pm 0.003$ & 16 & $<0.001$ \\
\hline $7 \cdot 52 \times 10^{-4} \pm 0.45 \times 10^{-4}$ & & $<0 \cdot 001$ \\
\hline
\end{tabular}


Table 2 Number of expressed and non-expressed genes. The table shows the number of genes absent or present in each of the growth plates. In the column defined as unknown is the number of genes not consistent in the present/absent analysis

Growth plate Tanner B2 Growth plate Tanner B3

\begin{tabular}{|c|c|c|}
\hline Absent & Present & Unknown \\
\hline 10255 & 5016 & 5555 \\
\hline 10118 & 5069 & 5639 \\
\hline
\end{tabular}

most upregulated gene, showing a 6.48-fold increase in expression and the most affected downregulated gene, pannexin 3 , showed a $2 \cdot 02$-fold decrease in expression level.

The 394 differentially expressed genes were further investigated with Fisher's exact tests using SAS and the KEGG database. Of the 394 genes, 111 could be mapped to 13 enriched pathways $(P<0 \cdot 05$; Table 3$)$. Several of the differentially expressed genes were present in more than one of the above pathways. These pathways were mostly related to the ECM, cell communication, and metabolism. We studied these genes independently for their up- or downregulation (Supplementary Table 3, see section on supplementary data given at the end of this article). Most genes, 89 out of 111 , were upregulated in the growth plate with progression of puberty. In addition, differentially expressed genes were further investigated with the Gene Ontology Tree Machine. This revealed 49 different $\mathrm{GO}$ terms relatively enriched $(P<0 \cdot 01)$. Enriched GO terms were related to the ECM, cell cycle, cell growth, and ligase activity (Supplementary Figure 1, see section on supplementary data given at the end of this article).

\section{Transcription factor binding sites}

We next scanned the promoter regions up to 5000nt upstream of the translation start site of the 394 differentially expressed genes for the presence of evolutionarily conserved transcription factor binding sites. We limited our search to transcription factor binding sites which are activated by hormones and paracrine factors that have previously been implicated in growth plate maturation: estrogen response elements (EREs) and androgen response element (ARE) for activity of sex steroids, STAT5B for GH (Rosenfeld \& Hwa 2009), ELK1 for IGF1 (Bruning et al. 2000), CREB for PTHrP (Mak et al. 2008), and Runx 2 for growth plate hypertrophy (Solomon et al. 2008). We limited our analysis to the top $0 \cdot 001 \%$ of the highest scoring motif sites in all the promoter regions, determined the evolutionary conservation score of these sites, and found 215 genes with one or more transcription factor binding motifs. The motifs and genes are listed in Supplementary Table 1. As a control, a similar analysis was performed using 100 sets of 394 randomly chosen genes and 100 randomized transcription factor binding motifs. These randomizations were used to calculate statistical confidence score $(P$ value). The data are summarized in Table 4.
We found 87 genes with a transcription factor binding site for RUNX2, 76\% of genes going up in expression and $24 \%$ going down in expression. The average evolutionary conservation score of the motif was significantly higher $(P<0 \cdot 01)$ compared with the findings in randomly chosen genes. Likewise, evolutionary conservation of the ELK1 (49 genes) and STAT5B (31 genes) binding sites in the panel of 394 genes associated with growth plate maturation was significantly higher than random. In marked contrast, the average evolutionary conservation scores of EREs (49 genes), AREs (46 genes), and CREB (44 genes) in the set of 394 genes were not significantly higher than in the randomized controls.

To verify that these motifs can actually be bound by the corresponding transcription factors, we searched the literature for known interactions with the corresponding genes. For each of the transcription factors, we found an overlap of genes that were shown to be bound in their promoter region by one or more of the transcription factors. For example, ChIP analysis of ELK1 binding in HeLa and Jurkat cells shows binding in nine of the genes found in our list of putative ELK1-regulated genes (Boros et al. 2009), and over 50 matches are found in genes that are shown to be bound by Runx2 in either ChIP-on-chip assays or responsive to modulations in Runx2 levels by siRNA knockdown experiments in both human and mouse cells (Young et al. 2007a,b, van der Deen et al. 2008, Teplyuk et al. 2008, $2009 a$ ). In summary, for ELK1, the identified transcription factor binding sites were confirmed in $21 \%$ of cases, RUNX2 57\%, CREB 23\%, ER 16\%, and AR 20\% (Supplementary Table 4 , see section on supplementary data given at the end of this article).

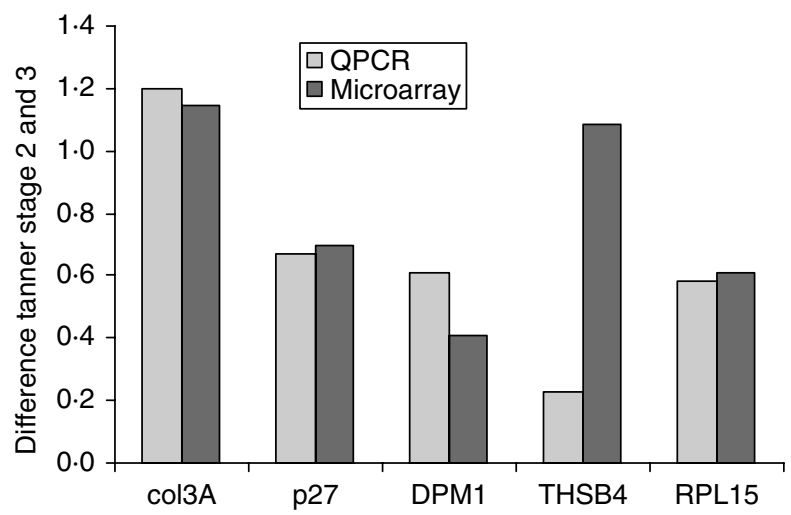

Figure 2 RT-PCR validation of microarray data. Correlation between RT-PCR and microarray results for (A) collagen $3 \mathrm{~A} 1$ (COL3A), (B) thrombospondin 4 (THBS4), (C) CDKN1B (p27Kip1),

(D) ribosomal protein L15 (RPL15), and (E) dolichyl-phosphate mannosyltransferase polypeptide 1 (DPM1). Results are expressed as changes with progression of puberty (value Tanner stage B3- Tanner stage B2) for both the RT-PCR $\left(\Delta C_{\mathrm{t}}=C_{\mathrm{t}_{\text {gene of interest }}}-C_{\mathrm{t}_{\beta_{2}-\text { microplobulin }}}\right)$ and the microarray results (least square means). Similar trends in gene expression (up- or downregulation) were found in qPCR and microarray analysis for all genes; however, THSB4 showed a more pronounced increase in expression in the microarray results compared with the qPCR results. 
Table 3 Pathways significantly changing with progression of puberty. The 13 significant pathways associated with pubertal maturation of the growth plate are shown

\begin{tabular}{|c|c|c|c|}
\hline Pathway & $\begin{array}{l}\text { Genes } \\
\text { found }\end{array}$ & $\begin{array}{l}\text { Total genes } \\
\text { pathway }\end{array}$ & $\%$ \\
\hline 1. Proteasome & 9 & 23 & 39 \\
\hline 2. Cholera infection & 10 & 30 & 33 \\
\hline 3. Oxidative phosphorylation & 20 & 89 & 22 \\
\hline 4. N Glycan biosynthesis & 9 & 27 & 33 \\
\hline 5. ATP synthesis & 9 & 28 & 32 \\
\hline 6. Adherens junction & 14 & 60 & 23 \\
\hline 7. Aminosugars metabolism & 6 & 17 & 35 \\
\hline 8. Regulation of autophagy & 6 & 17 & 35 \\
\hline 9. Ribosome & 9 & 35 & 26 \\
\hline 10. ECM receptor interaction & 14 & 67 & 21 \\
\hline 11. Cell cycle & 15 & 84 & 18 \\
\hline 12. Cell communication & 13 & 74 & 18 \\
\hline $\begin{array}{l}\text { 13. Ubiquitin-mediated } \\
\text { proteolysis }\end{array}$ & 7 & 32 & 22 \\
\hline
\end{tabular}

${ }^{*} P<0 \cdot 05,{ }^{+} P<0 \cdot 01,{ }^{\ddagger} P<0 \cdot 001$.

Finally, we addressed the question whether these transcription factors co-operate in the regulation of growth plate maturation. Therefore, we checked whether there was any overlap in the motifs found in the regulatory region of the target genes. We assumed that the probability of functional regulation is higher in genes that contain multiple conserved binding motifs, as found for some of the target genes of the ELK1 family member Ets1 and the androgen receptor (Massie et al. 2007). Indeed, we found that four out of the 43 genes with an ELK1 binding motif also contain an ARE motif. We found that $29 \cdot 6 \%$ of the genes contain motifs for two transcription factors and $3 \cdot 5 \%$ of the genes contain three or more motifs. We have visualized the co-regulation of the transcription factors in Supplementary Figure 2, see section on supplementary data given at the end of this article.

In summary, the highest scoring motif sites for RUNX2, ELK1, and STAT5B were also the most conserved across primates, suggesting that the presence of these motifs may play a functional role in the regulation of expression of the genes related to growth plate maturation. Conversely, high-scoring ER, AR, and CREBP motif sites were not better conserved than those in random gene sets, suggesting that their presence in the promoter regions investigated is coincidental.

\section{Discussion}

In this study, we compared gene expression levels in two unique human epiphyseal growth plate samples obtained from one girl at early and mid puberty (Tanner stage 2 and 3 ) with a 1 -year interval. Maturation of the epiphyseal growth plate in mid puberty is associated with a multitude of changes in morphology and expression levels of genes associated with the ECM, cell death, cell communication, and metabolism. In the panel of 394 genes changing with growth plate maturation, we found evidence, based on the evolutionary conservation of the highest scoring transcription factor binding sites, for regulation of expression by the transcription factors RUNX2, ELK-1, and STAT5B.

A limitation of our study is the small sample number. However, these growth plate samples are unique and enable a longitudinal analysis within one patient, thereby excluding genetic confounders. Adult height is determined for $80-90 \%$ by genetic factors (Tou et al. 2001, Perola et al. 2007). Inclusion of additional patients would, therefore, result in increased variability, which would complicate all subsequent analysis. To the best of our knowledge, no other microarray studies have been performed on human growth plate tissues. The observed changes in gene expression and subsequent pathway analysis were fully in line with morphological changes that are characteristic for growth plate maturation in animal studies. In addition, microarray data were confirmed by qPCR. This strengthens our confidence that the set of 394 genes is representative for changes in growth plate maturation and that our findings are biologically relevant. However, additional studies have to be done in a larger number of samples and with more pubertal stages to confirm our findings.

The patient in this study suffered from cerebral palsy, which to our knowledge does not interfere with the molecular mechanisms of growth plate maturation and fusion. These patients have normal longitudinal bone growth, normal

Table 4 Genes with a transcription factor binding site (TFBS) for each of the six motifs. Number and percentage of genes plus the average conservation score containing a TFBS for each of the six motifs. Results are presented for the top $0 \cdot 0001 \%$ of sites and top $0 \cdot 001 \%$ of sites. For each motif the percentage of genes going up and down in expression is given. The last column shows the number of genes that are found in ChIP or knock-down assays for the corresponding transcription factors

\begin{tabular}{|c|c|c|c|c|c|c|c|}
\hline Motifs & $\begin{array}{l}\text { No. of } \\
\text { genes }\end{array}$ & $\begin{array}{l}\% \text { of } 394 \\
\text { genes }\end{array}$ & $P$ value & $\begin{array}{l}\text { Average } \\
\text { conservation } \\
\text { score }\end{array}$ & $\begin{array}{l}\% \text { genes } \\
\text { up }\end{array}$ & $\begin{array}{l}\% \text { genes } \\
\text { down }\end{array}$ & $\begin{array}{l}\text { No. of TFBS } \\
\text { confirmed }\end{array}$ \\
\hline Estrogen receptor & 49 & 13 & $0 \cdot 25$ & $0 \cdot 19$ & 73 & 27 & 8 \\
\hline Elk-1 & 43 & 9 & $<0 \cdot 01$ & $0 \cdot 33$ & 70 & 30 & 9 \\
\hline STAT5B & 31 & 8 & $0 \cdot 04$ & $0 \cdot 25$ & 81 & 19 & 1 \\
\hline RUNX2 & 87 & 22 & $<0 \cdot 01$ & $0 \cdot 23$ & 76 & 24 & 50 \\
\hline Androgen receptor & 46 & 12 & $0 \cdot 07$ & $0 \cdot 22$ & 80 & 20 & 9 \\
\hline CREB & 44 & 11 & $0 \cdot 16$ & $0 \cdot 20$ & 75 & 25 & 10 \\
\hline
\end{tabular}


puberty, and at the end of puberty longitudinal growth also stops with fusion of the growth plate as seen in healthy individuals. Therefore, we safely assume that the underlying mechanism of epiphyseal maturation and fusion is the same for the growth plates of healthy individuals and our patient.

Histological experiments and measurements showed a clear decrease in total growth plate height with maturation. This is in line with the observations in rabbits, where growth plate height gradually declines with age and even more rapidly under the influence of estrogen (Weise et al. 2001). In humans, it is known (and widely used for assessing skeletal maturation) that radiographically the epiphyseal width varies in different stages and declines in its progress toward maturity. In the more mature growth plate, columns were more widely spaced with more ECM. These changes are described as senescence of the growth plate and confirm earlier results in rabbits and rats (Kember 1973, Weise et al. 2001). These changes in the ECM compartment with maturation of the growth plate were in line with the microarray results, demonstrating a significant change in expression of genes linked to ECM pathways. Histology shows that the absolute height of the growth plate changes during maturation, but not the relative height of the proliferative and hypertrophic zone (Table 1). This ratio is at least in part determined by the Ihh PTHrP feedback loop (Tryfonidou et al. 2010). Consequently, one would not expect differences in these pathways, and indeed, this is what we found (Supplementary Table 5, see section on supplementary data given at the end of this article).

The ECM receptor interaction pathway significantly changed with 14 out of 67 genes affected in this pathway. Both the pathways associated with the ECM, the aminosugars metabolism pathway and the $N$-glycan biosynthesis pathway, change significantly with maturation. The ECM is composed of a variety of macromolecules like proteoglycans and polysaccharides (glycosaminoglycans) that are secreted locally and assembled into an organized network (Toole \& Linsenmayer 1977, Toole et al. 1977). Most genes in these three pathways are upregulated with maturation implying an increase in pathway activity and ECM production. In addition to the pathway and morphology data, the GO term analyses also showed many enriched GO categories that are involved in and associated with the ECM, which strengthens our findings. Blanchard et al. (1991) demonstrated previously that estrogens and testosterone stimulate proteoglycan synthesis in vitro in male and female human epiphyseal chondrocytes, consistent with our results. Besides ECM pathways, not only cell death pathways were enriched in the differentially expressed gene sets, e.g. proapoptotic and anti-apoptotic genes, but also genes involved in the regulation of autophagy. Apoptosis and autophagy are closely related, and there is an overlap in signaling proteins (Codogno \& Meijer 2006, Heath-Engel et al. 2008). Previously, we found no signs of classical apoptosis in the human growth plate with pubertal maturation and epiphyseal fusion (Emons et al. 2009). The results of this study are in line with this and are suggestive for a non-classical and perhaps intermediate mechanism of different types of cell death.
The overall change in gene expression levels in growth plate chondrocytes with progression of puberty was unexpectedly small, since puberty is associated with dramatic changes in growth velocity and hormone levels like sex steroids, GH and IGF1 (Juul et al. 1994, Abbassi 1998, Casazza et al. 2008). Our microarray data are in line with the histological changes observed with growth plate maturation providing support that the differentially expressed gene set is representative for the changes that occur during growth plate maturation. We hypothesized that analysis of the promoter regions of these genes may provide clues for transcription factors and signaling pathways that are involved in growth plate maturation. More specifically, the promoter regions were analyzed for the presence of evolutionarily conserved binding sites for ER and androgen receptor, ELK-1 for IGF1, STAT5B for GH, CREB for PTHrP, and RUNX2 for growth plate hypertrophy.

Despite strong clinical and experimental evidence for the role of sex steroids and in particular estrogen in growth plate maturation, the potential EREs and also AREs in the promoter regions of the 394 genes were less conserved in other primate species. Although motif sites that are conserved between species are more likely to have a functional role (Siepel et al. 2005, Kouwenhoven et al. 2010), the EREs we identified upstream of the 394 differentially regulated genes may still be functional in human. In the current analysis, we assessed only the $0 \cdot 001 \%$ best matching motif sites in a promoter region of 5000nt upstream of the translation start site. We chose this rather conservative approach to minimize false positive predictions, which remains a challenge in bioinformatic transcription factor binding site prediction. Previous analyses have detected an ERE-mediated response in the hypertrophic zone of mice using reporter mice with a luciferase gene under the control of three EREs, enabling detection of in vivo activation of gene transcription (Windahl et al. 2007). It has been observed that most functional EREs and AREs are located far away from the transcription start site, and therefore these would not be found in our analysis (Carroll et al. 2006, Jariwala et al. 2007). However, 16\% of the genes with conserved ERE motifs in the 5000nt upstream of the TSS were confirmed with ChIP analysis and 20\% of the genes with conserved ARE motifs were confirmed by ChIP analysis (Table 4). So, although our stringency for the analysis is high, and ChIP data are only available for different tissues and cell types, we found that many of the putative interactions are indeed confirmed by ChIP analysis. This indicates that our method can be used to predict possible regulation of gene expression by these transcription factors in our human growth plates and provides clues as to which upstream signaling pathways are involved in the regulation of growth plate maturation. Our data do not exclude a role for non-genomic estrogen signaling in growth plate maturation nor for an indirect effect of estrogen. Likewise, no enrichment was found for CREB binding sites, which are activated by intracellular cAMP levels via, for example, PTHrP. 
In marked contrast, the high scoring ELK-1, STAT5B, and RUNX2 motif sites were conserved across primates. ELK-1 and STAT5B are activated by, amongst others, IGF1 and GH for which receptors are present in growth plate chondrocytes. In animal models, local effects of GH and IGF1 on growth plate chondrocytes have been established (Isgaard et al. 1986, Ohlsson et al. 1992). In addition to the increase in levels of estrogen, the levels of GH and IGF1 significantly increase with the progression of puberty. Moreover, it is well known that GH treatment accelerates growth as well as growth plate maturation, either directly or indirectly via IGF1. Our conservation analysis of the transcription factor binding motifs in the promoters of differentially expressed genes supports a direct role for GH and IGF1 in growth plate maturation, resulting in the activation of STAT5B- and ELK-1-mediated gene transcription respectively. The effect of estrogen on the activity of the GH/IGF1 axis is well appreciated, demonstrated by increasing $\mathrm{GH}$ levels in patients with oral estrogen treatment (Coutant et al. 2004, Veldhuis et al. 2008). This suggests that effects of estrogen on growth plate maturation might be mediated, at least in part, by GH and/or IGF1.

Runx2 plays an important role in the earliest stages of mouse chondrocyte maturation and hypertrophy, and Runx2 controls production of bone matrix proteins (Komori 2003, Lian et al. 2006). Our results are in line with this hypothesis, since we found many genes changing with maturation of the human growth plate in puberty that contained evolutionarily conserved transcription factor binding site for RUNX2. Previous studies have shown that RUNX2 can mediate actions of estrogen in an osteoblastic cell line and that selective ER modulators like tamoxifen and raloxifene can increase RUNX2 promoter activity in an osteosarcoma cell line (Sasaki-Iwaoka et al. 1999, Tou et al. 2001). In addition, RUNX2 is a direct regulator of the non-genomic ER GPR 30 (Teplyuk et al. 2008). These observations provide additional mechanisms by which estrogen can indirectly influence growth plate maturation. Several studies have examined Runx2-responsive genes in osteoprogenitors (Teplyuk et al. 2008, 2009a, 2009b), in mouse embryonic fibroblasts (MEFs; Wotton et al. 2008, Kilbey et al. 2010), and in osteosarcoma cells (Young et al. 2007a,b), as well as binding of Runx2 to promoters in genomic loci in osteosarcoma cells (van der Deen et al. 2008). Comparison of the corresponding gene lists reveals that at least $\sim 60 \%$ (50 of 87 ) of all genes predicted to have Runx 2 binding sites are regulated by Runx2, consistent with the biological role of Runx 2 and other Runx proteins in the development and function of the growth plate.

While the changes in growth plate morphology are in line with the senescence hypothesis, our data do not allow testing the proposed effect of estrogen on the depletion of stem-like cells in the growth plate with progression of puberty.

In conclusion, maturation of the epiphyseal growth plate in mid puberty is associated with morphological changes consistent with the senescence theory. This was corroborated by a multitude of changes in gene expression. In total, 13 pathways were affected with maturation, several related to the
ECM, the cell cycle, and the programmed cell death. We did not find support for direct genomic effects of estrogen, suggesting that the well appreciated role of estrogen in growth plate maturation might perhaps be indirect by modulating GH, IGF1, and RUNX2 activity. Evolutionary conservation of binding sites provides evidence for a direct role for $\mathrm{GH}$, IGF1, and RUNX2 in growth plate maturation.

\section{Supplementary data}

This is linked to the online version of the paper at http://dx.doi.org/10.1530/ JOE-10-0219.

\section{Declaration of interest}

The authors declare that there is no conflict of interest that could be perceived as prejudicing the impartiality of the research reported.

\section{Funding}

This study was supported by a Research Unit grant of the European Society for Paediatric Endocrinology. J E was supported by a grant from ZonMW, the Netherlands Organisation of Health and Research and Development (grant number 920-03-358). B E D was supported by a Horizon grant (050-71-058) from Netherlands Organisation for Scientific Research (NWO). E D and H P were supported by a grant from the Deutsche Forschungsgemeinschaft. This study was also supported by the National Institutes of Health Grants R01 AR49069 (to A J W) and R01 AR39588 (to G S Stein).

\section{Acknowledgements}

The authors thank the orthopedic surgeons in the Leiden University Medical Center for providing the growth plate samples. We thank Drs Margaretha van der Deen, Nadiya Teplyuk, Dan Young, and Victor Teplyuk (University of Massachusetts), as well as Drs Sandy Wotton and Anne Terry (University of Glasgow), for sharing their data on transcription factor targets. The authors thank Ir Jetse Scholma and Dr Marriana Tryfonidou for useful discussions.

\section{References}

Abbassi V 1998 Growth and normal puberty. Pediatrics 102 507-511. Beissbarth T 2006 Interpreting experimental results using gene ontologies. Methods in Enzymology 411 340-352. (doi:10.1016/S0076-6879(06)11018-6) Blanchard O, Tsagris L, Rappaport R, Duval-Beaupere G \& Corvol M 1991 Age-dependent responsiveness of rabbit and human cartilage cells to sex steroids in vitro. Journal of Steroid Biochemistry and Molecular Biology 40 711-716. (doi:10.1016/0960-0760(91)90295-G)

Boros J, Donaldson IJ, O’Donnell A, Odrowaz ZA, Zeef L, Lupien M, Meyer CA, Liu XS, Brown M \& Sharrocks AD 2009 Elucidation of the ELK1 target gene network reveals a role in the coordinate regulation of core components of the gene regulation machinery. Genome Research 19 1963-1973. (doi:10.1101/ gr.093047.109)

Bruning JC, Gillette JA, Zhao Y, Bjorbaeck C, Kotzka J, Knebel B, Avci H, Hanstein B, Lingohr P, Moller DE et al. 2000 Ribosomal subunit kinase-2 is required for growth factor-stimulated transcription of the c-Fos gene. PNAS 97 2462-2467. (doi:10.1073/pnas.97.6.2462)

Carroll JS, Meyer CA, Song J, Li W, Geistlinger TR, Eeckhoute J, Brodsky AS, Keeton EK, Fertuck KC, Hall GF et al. 2006 Genome-wide analysis of estrogen receptor binding sites. Nature Genetics 38 1289-1297. (doi:10.1038/ng1901) 
Casazza K, Goran MI \& Gower BA 2008 Associations among insulin, estrogen, and fat mass gain over the pubertal transition in African-American and European-American girls. Journal of Clinical Endocrinology and Metabolism 93 2610-2615. (doi:10.1210/jc.2007-2776)

Chagin AS \& Savendahl L 2007a Estrogens and growth: review. Pediatric Endocrinology Reviews 4 329-334.

Chagin AS \& Savendahl L 2007b GPR30 estrogen receptor expression in the growth plate declines as puberty progresses. Journal of Clinical Endocrinology and Metabolism 92 4873-4877. (doi:10.1210/jc.2007-0814)

Chu TM, Weir B \& Wolfinger R 2002 A systematic statistical linear modeling approach to oligonucleotide array experiments. Mathematical Biosciences 176 35-51. (doi:10.1016/S0025-5564(01)00107-9)

Codogno P \& Meijer AJ 2006 Atg5: more than an autophagy factor. Nature Cell Biology 8 1045-1047. (doi:10.1038/ncb1006-1045)

Coutant R, de Casson FB, Rouleau S, Douay O, Mathieu E, Gatelais F, Bouhours-Nouet N, Voinot C, Audran M \& Limal JM 2004 Divergent effect of endogenous and exogenous sex steroids on the insulin-like growth factor I response to growth hormone in short normal adolescents. Journal of Clinical Endocrinology and Metabolism 89 6185-6192. (doi:10.1210/jc.20040814)

van der Deen M, Hassan MQ, Pratap J, Teplyuk NM, Young DW, Javed A, Zaidi SK, Lian JB, Montecino M, Stein JL et al. 2008 Chromatin immunoprecipitation assays: application of ChIP-on-chip for defining dynamic transcriptional mechanisms in bone cells. Methods in Molecular Biology 455 165-176. (doi:10.1007/978-1-59745-104-8_13)

van der Eerden BC, Karperien M, Gevers EF, Lowik CW \& Wit JM 2000 Expression of Indian hedgehog, parathyroid hormone-related protein, and their receptors in the postnatal growth plate of the rat: evidence for a locally acting growth restraining feedback loop after birth. Journal of Bone and Mineral Research 15 1045-1055. (doi:10.1359/jbmr.2000.15.6.1045)

Emons J, Chagin AS, Hultenby K, Zhivotovsky B, Wit JM, Karperien M \& Savendahl L 2009 Epiphyseal fusion in the human growth plate does not involve classical apoptosis. Pediatric Research 66 654-659. (doi:10.1203/ PDR.0b013e3181beaa8c)

Filardo EJ, Quinn JA, Frackelton AR Jr \& Bland KI 2002 Estrogen action via the G protein-coupled receptor, GPR30: stimulation of adenylyl cyclase and CAMP-mediated attenuation of the epidermal growth factor receptorto-MAPK signaling axis. Molecular Endocrinology 16 70-84. (doi:10.1210/ me.16.1.70)

Gafni RI, Weise M, Robrecht DT, Meyers JL, Barnes KM, De Levi S \& Baron J 2001 Catch-up growth is associated with delayed senescence of the growth plate in rabbits. Pediatric Research 50 618-623. (doi:10.1203/00006450200111000-00014)

Greene GL, Gilna P, Waterfield M, Baker A, Hort Y \& Shine J 1986 Sequence and expression of human estrogen receptor complementary DNA. Science 231 1150-1154. (doi:10.1126/science.3753802)

Haider S, Ballester B, Smedley D, Zhang J, Rice P \& Kasprzyk A 2009 BioMart central Portal-unified access to biological data. Nucleic Acids Research 37 W23-W27. (doi:10.1093/nar/gkp265)

Heath-Engel HM, Chang NC \& Shore GC 2008 The endoplasmic reticulum in apoptosis and autophagy: role of the BCL-2 protein family. Oncogene $\mathbf{2 7}$ 6419-6433. (doi:10.1038/onc.2008.309)

Heinrichs C, Yanovski JA, Roth AH, Yu YM, Domene HM, Yano K, Cutler GB Jr \& Baron J 1994 Dexamethasone increases growth hormone receptor messenger ribonucleic acid levels in liver and growth plate. Endocrinology 135 1113-1118. (doi:10.1210/en.135.3.1113)

Isgaard J, Nilsson A, Lindahl A, Jansson JO \& Isaksson OGP 1986 Effects of local-administration of Gh and Igf-1 on longitudinal bone-growth in rats. American Journal of Physiology 250 E367-E372.

Jariwala U, Prescott J, Jia L, Barski A, Pregizer S, Cogan JP, Arasheben A, Tilley WD, Scher HI, Gerald WL et al. 2007 Identification of novel androgen receptor target genes in prostate cancer. Molecular Cancer 639. (doi:10.1186/1476-4598-6-39)

Juul A, Bang P, Hertel NT, Main K, Dalgaard P, Jorgensen K, Muller J, Hall K \& Skakkebaek NE 1994 Serum insulin-like growth factor-I in 1030 healthy children, adolescents, and adults: relation to age, sex, stage of puberty, testicular size, and body mass index. Journal of Clinical Endocrinology and Metabolism 78 744-752. (doi:10.1210/jc.78.3.744)
Kamp GA, Waelkens JJ, de Muinck Keizer-Schrama SM, Delemarre-van de Waal HA, Verhoeven-Wind L, Zwinderman AH \& Wit JM 2002 High dose growth hormone treatment induces acceleration of skeletal maturation and an earlier onset of puberty in children with idiopathic short stature. Archives of Disease in Childhood 87 215-220. (doi:10.1136/adc.87.3.215)

Karp SJ, Schipani E, St-Jacques B, Hunzelman J, Kronenberg H \& McMahon AP 2000 Indian hedgehog coordinates endochondral bone growth and morphogenesis via parathyroid hormone related-protein-dependent and independent pathways. Development 127 543-548.

Kember NF 1973 Aspects of the maturation process in growth cartilage in the rat tibia. Clinical Orthopaedics and Related Research 95 288-294.

Kilbey A, Terry A, Jenkins A, Borland G, Zhang Q, Wakelam MJ, Cameron ER \& Neil JC 2010 Runx regulation of sphingolipid metabolism and survival signaling. Cancer Research 70 5860-5869. (doi:10.1158/0008-5472. CAN-10-0726)

Kindblom JM, Nilsson O, Hurme T, Ohlsson C \& Savendahl L 2002 Expression and localization of Indian hedgehog (Ihh) and parathyroid hormone related protein (PTHrP) in the human growth plate during pubertal development. Journal of Endocrinology 174 R1-R6. (doi:10.1677/ joe.0.174R001)

Komori T 2003 Requisite roles of Runx2 and Cbfb in skeletal development. Journal of Bone and Mineral Metabolism 21 193-197.

Kouwenhoven EN, van Heeringen SJ, Tena JJ, Oti M, Dutilh BE, Alonso ME, de 1C-M, Smeenk L, Rinne T, Parsaulian L et al. 2010 Genome-wide profiling of 63 DNA-binding sites identifies an element that regulates gene expression during limb development in the 7q21 SHFM1 locus. PLoS Genetics 6 e1001065. (doi:10.1371/journal.pgen.1001065)

Kronenberg HM 2003 Developmental regulation of the growth plate. Nature 423 332-336. (doi:10.1038/nature01657)

Kuhn RM, Karolchik D, Zweig AS, Wang T, Smith KE, Rosenbloom KR, Rhead B, Raney BJ, Pohl A, Pheasant M et al. 2009 The UCSC genome browser database: update 2009. Nucleic Acids Research 37 D755-D761. (doi:10.1093/nar/gkn875)

Lian JB, Stein GS, Javed A, van Wijnen AJ, Stein JL, Montecino M, Hassan MQ, Gaur T, Lengner CJ \& Young DW 2006 Networks and hubs for the transcriptional control of osteoblastogenesis. Reviews in Endocrine and Metabolic Disorders 7 1-16. (doi:10.1007/s11154-006-9001-5)

MacGillivray MH, Morishima A, Conte F, Grumbach M \& Smith EP 1998 Pediatric endocrinology update: an overview. The essential roles of estrogens in pubertal growth, epiphyseal fusion and bone turnover: lessons from mutations in the genes for aromatase and the estrogen receptor. Hormone Research 49 (Suppl 1) 2-8. (doi:10.1159/000053061)

Mak KK, Bi Y, Wan C, Chuang PT, Clemens T, Young M \& Yang Y 2008 Hedgehog signaling in mature osteoblasts regulates bone formation and resorption by controlling PTHrP and RANKL expression. Developmental Cell 14 674-688. (doi:10.1016/j.devcel.2008.02.003)

Massie CE, Adryan B, Barbosa-Morais NL, Lynch AG, Tran MG, Neal DE \& Mills IG 2007 New androgen receptor genomic targets show an interaction with the ETS1 transcription factor. EMBO Reports 8 871-878. (doi:10. 1038/sj.embor.7401046)

Morishima A, Grumbach MM, Simpson ER, Fisher C \& Qin K 1995 Aromatase deficiency in male and female siblings caused by a novel mutation and the physiological role of estrogens. Journal of Clinical Endocrinology and Metabolism 80 3689-3698. (doi:10.1210/jc.80.12.3689)

Nilsson O, Chrysis D, Pajulo O, Boman A, Holst M, Rubinstein J, Martin RE \& Savendahl L 2003 Localization of estrogen receptors-alpha and -beta and androgen receptor in the human growth plate at different pubertal stages. Journal of Endocrinology 177 319-326. (doi:10.1677/joe.0.1770319)

Ohlsson C, Nilsson A, Isaksson O \& Lindahl A 1992 Growth hormone induces multiplication of the slowly cycling germinal cells of the rat tibial growth plate. PNAS 89 9826-9830. (doi:10.1073/pnas.89.20.9826)

Perola M, Sammalisto S, Hiekkalinna T, Martin NG, Visscher PM, Montgomery GW, Benyamin B, Harris JR, Boomsma D, Willemsen G et al. 2007 Combined genome scans for body stature in 6,602 European twins: evidence for common Caucasian loci. PLoS Genetics 3 e97. (doi:10. 1371/journal.pgen.0030097) 
Perry RJ, Farquharson C \& Ahmed SF 2008 The role of sex steroids in controlling pubertal growth. Clinical Endocrinology 68 4-15. (doi:10.1111/j. 1365-2265.2007.02960.x)

Portales-Casamar E, Kirov S, Lim J, Lithwick S, Swanson MI, Ticoll A, Snoddy J \& Wasserman WW 2007 PAZAR: a framework for collection and dissemination of cis-regulatory sequence annotation. Genome Biology 8 R207. (doi:10.1186/gb-2007-8-10-r207)

Roche PJ, Hoare SA \& Parker MG 1992 A consensus DNA-binding site for the androgen receptor. Molecular Endocrinology 6 2229-2235. (doi:10.1210/ me.6.12.2229)

Rosenfeld RG \& Hwa V 2009 The growth hormone cascade and its role in mammalian growth. Hormone Research 71 (Suppl 2) 36-40. (doi:10.1159/ 000192434)

Sandberg R \& Larsson O 2007 Improved precision and accuracy for microarrays using updated probe set definitions. BMC Bioinformatics 848 . (doi:10.1186/1471-2105-8-48)

Sandelin A, Wasserman WW \& Lenhard B 2004 ConSite: web-based prediction of regulatory elements using cross-species comparison. Nucleic Acids Research 32 W249-W252. (doi:10.1093/nar/gkh372)

Sasaki-Iwaoka H, Maruyama K, Endoh H, Komori T, Kato S \& Kawashima H 1999 A trans-acting enhancer modulates estrogen-mediated transcription of reporter genes in osteoblasts. Journal of Bone and Mineral Research 14 248-255. (doi:10.1359/jbmr.1999.14.2.248)

Schrier L, Ferns SP, Barnes KM, Emons JA, Newman EI, Nilsson O \& Baron J 2006 Depletion of resting zone chondrocytes during growth plate senescence. Journal of Endocrinology 189 27-36. (doi:10.1677/joe.1.06489)

Siepel A, Bejerano G, Pedersen JS, Hinrichs AS, Hou M, Rosenbloom K, Clawson H, Spieth J, Hillier LW, Richards S et al. 2005 Evolutionarily conserved elements in vertebrate, insect, worm, and yeast genomes. Genome Research 15 1034-1050. (doi:10.1101/gr.3715005)

Smith EP, Boyd J, Frank GR, Takahashi H, Cohen RM, Specker B, Williams TC, Lubahn DB \& Korach KS 1994 Estrogen resistance caused by a mutation in the estrogen-receptor gene in a man. New England Journal of Medicine 331 1056-1061. (doi:10.1056/NEJM199410203311604)

Soldaini E, John S, Moro S, Bollenbacher J, Schindler U \& Leonard WJ 2000 DNA binding site selection of dimeric and tetrameric Stat 5 proteins reveals a large repertoire of divergent tetrameric Stat5a binding sites. Molecular and Cellular Biology 20 389-401. (doi:10.1128/MCB.20.1.389-401.2000)

Solomon LA, Berube NG \& Beier F 2008 Transcriptional regulators of chondrocyte hypertrophy. Birth Defects Research. Part C, Embryo Today 84 123-130. (doi:10.1002/bdrc.20124)

Tagle DA, Koop BF, Goodman M, Slightom JL, Hess DL \& Jones RT 1988 Embryonic epsilon and gamma globin genes of a prosimian primate (Galago crassicaudatus). Nucleotide and amino acid sequences, developmental regulation and phylogenetic footprints. Journal of Molecular Biology 203 439-455. (doi:10.1016/0022-2836(88)90011-3)

Teplyuk NM, Galindo M, Teplyuk VI, Pratap J, Young DW, Lapointe D, Javed A, Stein JL, Lian JB, Stein GS et al. 2008 Runx2 regulates G proteincoupled signaling pathways to control growth of osteoblast progenitors. Journal of Biological Chemistry 283 27585-27597. (doi:10.1074/jbc. M802453200)

Teplyuk NM, Haupt LM, Ling L, Dombrowski C, Mun FK, Nathan SS, Lian JB, Stein JL, Stein GS, Cool SM et al. 2009a The osteogenic transcription factor runx2 regulates components of the fibroblast growth factor/proteoglycan signaling axis in osteoblasts. Journal of Cellular Biochemistry 107 144-154. (doi:10.1002/jcb.22108)

Teplyuk NM, Zhang Y, Lou Y, Hawse JR, Hassan MQ, Teplyuk VI, Pratap J, Galindo M, Stein JL, Stein GS et al. $2009 b$ The osteogenic transcription factor runx2 controls genes involved in sterol/steroid metabolism, including CYP11A1 in osteoblasts. Molecular Endocrinology 23 849-861. (doi:10.1210/me.2008-0270)

Toole BP \& Linsenmayer TF 1977 Newer knowledge of skeletogenesis: macromolecular transitions in the extracellular matrix. Clinical Orthopaedics and Related Research 129 258-278.

Toole BP, Okayama M, Orkin RW, Yoshimura M, Muto M \& Kaji A 1977 Developmental roles of hyaluronate and chondroitin sulfate proteoglycans. Society of General Physiologists Series 32 139-154.
Tou L, Quibria N \& Alexander JM 2001 Regulation of human cbfa1 gene transcription in osteoblasts by selective estrogen receptor modulators (SERMs). Molecular and Cellular Endocrinology 183 71-79. (doi:10.1016/ S0303-7207(01)00594-9)

Treisman R, Marais R \& Wynne J 1992 Spatial flexibility in ternary complexes between SRF and its accessory proteins. EMBO Journal 11 4631-4640.

Tryfonidou MA, Hazewinkel HA, Riemers FM, Brinkhof B, Penning LC \& Karperien M 2010 Intraspecies disparity in growth rate is associated with differences in expression of local growth plate regulators. American Journal of Physiology. Endocrinology and Metabolism 299 E1044-E1052. (doi:10.1152/ ajpendo.00170.2010)

Turner RT, Riggs BL \& Spelsberg TC 1994 Skeletal effects of estrogen. Endocrine Reviews 15 275-300. (doi:10.1210/edrv-15-3-275)

Veldhuis JD, Keenan DM, Bailey JN, Adeniji A, Miles JM, Paulo R, Cosma M \& Soares-Welch C 2008 Estradiol supplementation in postmenopausal women attenuates suppression of pulsatile growth hormone secretion by recombinant human insulin-like growth factor type I. Journal of Clinical Endocrinology and Metabolism 93 4471-4478. (doi:10.1210/jc.2008-1493)

Vidal O, Lindberg M, Savendahl L, Lubahn DB, Ritzen EM, Gustafsson JA \& Ohlsson C 1999 Disproportional body growth in female estrogen receptoralpha-inactivated mice. Biochemical and Biophysical Research Communications 265 569-571. (doi:10.1006/bbrc.1999.1711)

Weise M, De Levi S, Barnes KM, Gafni RI, Abad V \& Baron J 2001 Effects of estrogen on growth plate senescence and epiphyseal fusion. PNAS 98 6871-6876. (doi:10.1073/pnas.121180498)

Welboren WJ, van Driel MA, Janssen-Megens EM, van Heeringen SJ, Sweep FC, Span PN \& Stunnenberg HG 2009 ChIP-Seq of ERalpha and RNA polymerase II defines genes differentially responding to ligands. $E M B O$ Journal 28 1418-1428. (doi:10.1038/emboj.2009.88)

Werther GA, Haynes K, Edmonson S, Oakes S, Buchanan CJ, Herington AC \& Waters MJ 1993 Identification of growth hormone receptors on human growth plate chondrocytes. Acta Paediatrica 82 (Suppl 391) 50-53. (doi:10. 1111/j.1651-2227.1993.tb12929.x)

Windahl SH, Lagerquist MK, Andersson N, Jochems C, Kallkopf A, Hakansson C, Inzunza J, Gustafsson JA, van der Saag PT, Carlsten H et al. 2007 Identification of target cells for the genomic effects of estrogens in bone. Endocrinology 148 5688-5695. (doi:10.1210/en.2007-0508)

Wotton S, Terry A, Kilbey A, Jenkins A, Herzyk P, Cameron E \& Neil JC 2008 Gene array analysis reveals a common Runx transcriptional programme controlling cell adhesion and survival. Oncogene 27 5856-5866. (doi:10.1038/onc.2008.195)

Yoshida CA \& Komori T 2005 Role of Runx proteins in chondrogenesis. Critical Reviews in Eukaryotic Gene Expression 15 243-254.

Yoshida CA, Yamamoto H, Fujita T, Furuichi T, Ito K, Inoue K, Yamana K, Zanma A, Takada K, Ito Y et al. 2004 Runx2 and Runx3 are essential for chondrocyte maturation, and Runx2 regulates limb growth through induction of Indian hedgehog. Genes and Development 18 952-963. (doi:10.1101/gad.1174704)

Young DW, Hassan MQ, Pratap J, Galindo M, Zaidi SK, Lee SH, Yang X, Xie R, Javed A, Underwood JM et al. 2007a Mitotic occupancy and lineage-specific transcriptional control of rRNA genes by Runx2. Nature 445 442-446. (doi:10.1038/nature05473)

Young DW, Hassan MQ, Yang XQ, Galindo M, Javed A, Zaidi SK, Furcinitti P, Lapointe D, Montecino M, Lian JB et al. 2007b Mitotic retention of gene expression patterns by the cell fate-determining transcription factor Runx2. PNAS 104 3189-3194. (doi:10.1073/pnas.0611419104)

de Zegher F, Butenandt O, Chatelain P, Albertsson-Wikland K, Jonsson B, Lofstrom A \& Chaussain JL 1997 Growth hormone treatment of short children born small for gestational age: reappraisal of the rate of bone maturation over 2 years and metanalysis of height gain over 4 years. Acta Paediatrica. Supplement 423 207-212.

Received in final form 20 January 2011

Accepted 9 February 2011

Made available online as an Accepted Preprint 9 February 2011 